\title{
ALGUNAS CONSIDERACIONES ACERCA DEL ABITO Y ARMADURA DE DIEGO DE CABRANES
}

Hace ahora más de dos decenios publicó el profesor Fernando Checa Cremades un interesante artículo destinado al análisis de algunas de las ideas estéticas que se pueden espigar en los capítulos XL, XXXVIII, XLI y XLII del tratado Abito y armadura spiritual, obra de Diego de Cabranes, meritoria aproximación a un texto prácticamente desconocido a pesar de su importancia como precedente de los innumerables tratados postridentinos que se ocuparán de la producción de las imágenes en el campo católico ${ }^{1}$.

Entre las conclusiones a las que llega el profesor Checa en su trabajo, destacaremos las siguientes:

1. Diego de Cabranes parece desconocer la palabra arquitecto. Utiliza el término «edificador» (p. 52).

2. Los ejes sobre los que gira su teoría de la imagen religiosa son la fe y la fidelidad a la naturaleza; «y en esto Cabranes se muestra plenamente de su tiempo. Y aun anticipador, por lo que respecta al ya señalado contrarreformismo de algunas de sus ideas» (p. 60).

En 1544 sale de la imprenta el voluminoso tratado de Diego de Cabranes ${ }^{2}$. Maestro en la Universidad de Salamanca, allí compuso la obra que nos ocupa. El Abito es una alegoría de las piezas de la armadura que el caballero cristiano debe portar para resistir los embates del mundo ${ }^{3}$ : el jubón o almila (los dones del Espíritu Santo), el arnés (la justicia divina), el escarpe (para la preparación evangélica), el escudo de la fe ${ }^{4}$, el almanete (defensor de la cabeza), la espada (palabra de Dios).

En la obra, tal y como señala Andrés Martín en su estudio preliminar a la edición citada en la nota 2, abundan las referencias a la auctoritas de Santo Tomás de Aquino y de Escoto. Además, el propio título podría aludir al fundamental Enchridion de Erasmo de Rotterdam. Sin embargo, hasta donde hemos podido saber, parece haberse pasado por alto un autor fundamental para explicar, precisamente, el tenor con que Diego de Cabranes aborda las cuestiones analizadas en el trabajo del profesor Checa. Efectivamente, junto a las copiosas citas de los dos grandes teólogos medievales encontramos, en el capítulo XXXVIIII (De los artifices y que saben officios) una alusión al «arçobispo de Florencia».

Antonio di Niccolò di ser Pierozzi (1389-1459), San Antonino, reformador de la observancia del convento de San Marco, hoy celebérrimo por los frescos que Fra Angelico pintó

\footnotetext{
I F. Checa Cremades, «Clasicismo, mentalidad religiosa e imagen artística: las ideas estéticas de Diego de Cabranes», Revista de Ideas Estéticas, 145, Tomo XXXVII, 1979, 51-60. Los capítulos van citados según aparecen en la edición princeps, que luego mencionaremos.

${ }^{2}$ Diego de Cabranes, Abito y armadura spiritual: compuesta por el maestro Diego de Cabranes, religioso de la orden de cauallería de Santiago del espada; capellán de su Magestad y vicario perpetuo de la ciudad de Mérida. MDXLIIII. El volumen, de difícil consulta, es ahora perfectamente accesible gracias a los buenos oficios de don Melquíades Andrés Martín y la Unión de Bibliófilos de Extremadura, quienes hicieron posible la publicación de una edición facsimilar en 1994.

${ }^{3}$ Seguimos aquí a Andrés Martín, op. cit., p. 13. Una excelente exposición del desarrollo en el pensamiento y la iconografía medievales de la imagen del miles Christi puede ser consultado en M. Evans, «An Illustrated Fragment of Peraldu's Summa of Vice: Harleian MS 3244», Journal of the Warburg and Courtauld Institutes, XLV, 1982, 14-68.

4 Alusión a la Trinidad (Fig. 1); según M. Evans fue Hugo de Saint Cher quien por primera vez consideró el scutum Fidei como un símbolo trinitario. Es obligado recordar aquí a Plutarco, quien en sus Moralia afirmó, citando a Xenócrates, que el triángulo equilátero es apropiado para expresar «la naturaleza de los dioses» (F. C. Babbit (ed.) Plutarch's Moralia, Cambridge (Mass.) y Londres, 1962).
}

$A E A, \mathrm{LXXV}, 2002,298$, pp. 191 a 216 
en sus celdas quizás con el asesoramiento del propio prior ${ }^{5}$, ocupó la cátedra arzobispal de Florencia a partir de 1446. Participó activamente en el célebre Concilio de Florencia (14391445), en el cual se buscó limar las diferencias entre las iglesias bizantina y romana. Una de sus facetas más celebradas fue la de predicador, que le otorgó merecida fama en una ciudad cuyo urbanismo debe mucho a la necesidad de albergar a las multitudes ávidas de escuchar inflamados sermones ${ }^{6}$. Su vida, guiada por el amor al prójimo y un acendrado sentido de la justicia, le hizo merecedor de una pronta canonización: en 1523 el papa Adriano VI lo colocó entre los santos. De hecho, ya Nicolás V, quien le pedía frecuentemente consejo en las cuestiones espirituales y temporales, llegó a afirmar que el dominico era digno de ser elevado a los altares antes de abandonar este mundo ${ }^{7}$.

A la faceta de predicador hay que unir su aguda capacidad de escrutinio de la sociedad que le tocó dirigir espiritualmente. Diferentes autores están de acuerdo en que sus análisis de la economía florentina lo convierten en un adelantado a su tiempo ${ }^{8}$. Entre su vasta producción escrita destaca la Summa Theologica Moralis. El profesor Gilbert la data «entre 1446 y 1459», es decir, entre el año en que ascendió a la cátedra florentina y el de su muerte ${ }^{9}$. Sin embargo, como señaló recientemente P. F. Howard, las prédicas de San Antonino constituyen la base para su obra más importante, que conoció, pues, una primera versión oral previa a la redacción definitiva que se dilataría unos catorce años $(1440-1454)^{10}$. El mismo autor asegura que, aunque la primera edición de la Summa vio la luz en 1456, sus ideas circularon ampliamente por la ciudad mediante manuscritos y, evidentemente, por su inicial función de sermones. Editada en cuatro gruesos volúmenes, la obra constituye, sin duda, el canto de cisne de aquellos tratados que, en palabras de Southern «tuvieron una vida extraordinariamente larga, y el término de su indiscutida utilidad, en el siglo xviI, señala el fin de la Edad Media más decisivamente que el Renacimiento o la Reforma»" ${ }^{1}$. En sus densas páginas encontramos moralizaciones sobre los más variados temas: la política, el matrimonio, el comercio... No es de extrañar, pues, que dedique varios capítulos (los abarcados en el Título VIII del Libro III) a una larga serie de oficios, entre los que se cuentan el de los barberos, los mercaderes, los joyeros, los arquitectos o los pintores, entre otros ${ }^{12}$.

La Summa gozó de un notable éxito. Piero Bargellini afirma que San Antonino fue el

\footnotetext{
${ }^{5}$ Tal es la hipótesis de M. Boskovits, «La fase tarda del Beato Angelico: una proposta di interpretazione», Arte Cristiana, LXXI/694 (1983), pp.11-24. Id., Immagini da meditare: ricerche su dipinti di tema religioso nei secoli XII-XV, Milán, 1994. Entre los primeros autores que han defendido la influencia ejercida por el arzobispo sobre los artistas de la primera generación del Renacimiento florentino se cuenta F. Hartt (Donatello, prophet of modern vision, Nueva York, 1973), a quien se sumó A. Paolucci, «Ghiberti orafo. Ghiberti e la sua arte nella Firenze del '3-'400», en Firenze, Città di Vita, Florencia, 1979, pp. 115-132. G. Scotti cree que la decoración mural de la Capilla Portinari, dedicada en San Eustorgio de Milán al dominicano San Pedro Mártir, depende en buena medida de la Summa antonina: "Alcune ipotesi di lettura per gli affreschi della Capella Portinari alla luce degli scritti di S. Antonino vescovo di Firenze», Arte Lombarda, 64, 1983, 65-78.

${ }^{6}$ De él Pío II, el gran papa humanista, dejó escrito en sus Comentarii: «Praedicator acceptus a popolo, quamvis scelerum insectator vehemens» (cit. en P. F. Howard, Beyond the Written Word: preaching and theology in the Florence of Archbishop Antoninus, 1427-1459, Florencia, 1995, 5).

${ }^{7}$ La escrita por R. Morçay sigue siendo la mejor biografía del dominico: Saint Antonin, Fondateur du Convent de Saint Marc, Archevêque de Florence, París, 1913.

${ }^{8}$ R. de Roover, San Bernardino of Siena and Sant'Antonino of Florence: The Two Great Economic Thinkers of the Middle Ages, Boston, 1967.

${ }^{9}$ C. Gilbert, «The Archbishop on the Painters of Florence», The Art Bulletin, XLI, 1959, 75-87.

${ }^{10}$ Op. cit., 30 ss. El trabajo de Howard (la oralidad previa a la palabra escrita) va en dirección opuesta a los de autores como J. D. Gellrich, quien sostiene la primacía de la escritura en la Edad Media («The Art of the Tongue: Illuminating Speech and Writing in Later Medieval Manuscripts», en C. Hourihane (ed.), Virtue and Vice: The Personifications in the Index of Christian Art, New Jersey, Princeton University Press, 2000, 93-119, con bibliografía).

11 R. W. Southern, La formación de la Edad Media, Madrid, 1980, 220.

12 Todo ello bajo el título «De statu mercatorum et artificum».
} 
moralista más consultado durante al menos dos centurias y media ${ }^{13}$. Más sobrio y concreto, U. Tucci indica que entre 1477 y 1600 la Summa conoció veinte ediciones ${ }^{14}$.

Independientemente de la cuestión de si la obra del arzobispo fue o no muy tenida en cuenta en la Península Ibérica, algo que escapa a los límites del presente trabajo ${ }^{15}$, la comparación entre algunos párrafos de su Summa y los del Abito que en su momento ocuparon al profesor Checa será prueba suficiente de que el maestro Diego de Cabranes conoció (y reconoció) la obra del insigne predicador. Así, por ejemplo, dice Cabranes en su capítulo XL, De los edificadores:

«Esta arte es necessaria a la vida humana para nuestra recreación y quietud: y ansí como conviene muchas vezes hazer retraymientos, cuyo inventor se lee ser el primero Cayn que mató a Abel su hermano elegido justo de Dios que edificó una y algunas casas como se lee en la escriptura (Gen. 4) : y después del diluvio : Nemrroth : el primer tirano que començó el edifficio de la torre de babilonia : y ansí confusos por su sobervia y división de lenguas que uvo en los que le siguieron fue necessario que la dexassen imperfecta».

Líneas que pueden compararse con las escritas por San Antonino en III, Tit. VIII, Cap. IV, S. VIII ${ }^{16}$ :

«De architectis seu aedificatoribus huiusmodi. Haec ars satis necessaria est vitae humanae per domibus et habitationibus faciendis quae nos defendat a pluviis et ventis frigoribus et caminatibus : ut quiescere valeat et secrete operari quae expedit. Primus Cayn reprobus legit edificasse civitatem unam et domos. Gen. IIII. Post diluvium autem Nemroth. Gen. X. primus tyrannus alios ad turrim aedificandum babel induxit. Gen. XI. ubi confusis ob superbia illorum linguis oportuit aedificium illud imperfectum dimittere».

El párrafo es, con ligeras variantes, el mismo. Cabranes conoció, pues, necesariamente el término «arquitecto» y su aplicación. Comparemos otros dos parágrafos de ambos autores:

Diego de Cabranes, cap. XXXVIII, De los carpinteros:

«[...] El cual puede pecar en el cortar madera no guardando ala menguante de la Luna por superstición maleficiosa considerando las mágicas fantasías de invenciones que Satanás induze a los fieles: mas si guardan estos tiempos según regla natural astrológica, según que la Luna cuando es más propinqua a los planetas que es en su crecimiento que influye en estas partes inferiores porosidades y ventosidades en disposiciones dañosas al corte de la madera y ansí se corrompe no considerando la menguante ni teniendo respeto a ella no pecan: porque por esperiencia se vee que la madera que se corta en menguante se conserva más de corrupción que no la que se corta en el lleno de la luna: ansí mismo obrando diversas obras trabajando en la traça de la madera es licito recebir por su trabajo salario según la cantidad e industria que puso».

\footnotetext{
13 «Mentre tante famosissimi libri del tempo venivano letti a stento da una limitatissima cerchia di studiosi, le opere di Antonino, e specialmente la Summa moralis, ebbero una grandisima fortuna. Dalla fine del Quattrocento al principio del Settecento le edizioni si susseguirono frequentemente. Antonino dei consigli fu per almen due secoli e mezzo il moralista più consultato», Sant'Antonino da Firenze, Brescia, 1941, 276.

14 «Le arti meccaniche in Sant'Antonino», en Idem (ed.) Studi in memoria di Giovanni Cassandro, Roma, 1991, vol. 3, 1065-1081. Hemos consultado la edición de 1516, Repertorium totius summe auree domini Antonini, salida de la imprenta de Joannes Clein en Lyon.

${ }^{15}$ El importante teólogo Francisco Suárez (1548-1617) basa algunas de sus teorías en los escritos de San Antonino (debemos esta información al profesor William McCuaig, de la Universidad de Toronto). Como nota curiosa citar la relación establecida entre la reina Leonor de Portugal (1458-1525) y la ciudad de Florencia tras el encuentro fortuito con una monja que tuviera problemas en la ciudad del Arno a raíz de una carta escrita por un sacerdote en nombre del arzobispo (K. Lowe, «Raínha D. Leonor of Portugal's Patronage in Renaissance Florence and Cultural Exchange», en Idem (ed.), Cultural Links Between Portugal and Italy in the Renaissance, Oxford, 2000, 225-248)

${ }^{16}$ El texto ofrece varios problemas de concordancia debidos, sin duda alguna, al cajista. Agradecemos sus indicaciones a los profesores Dolores Gómez y Antonio Navarrete.
}

AEA, LXXV, 2002, 298, pp. 191 a 216 

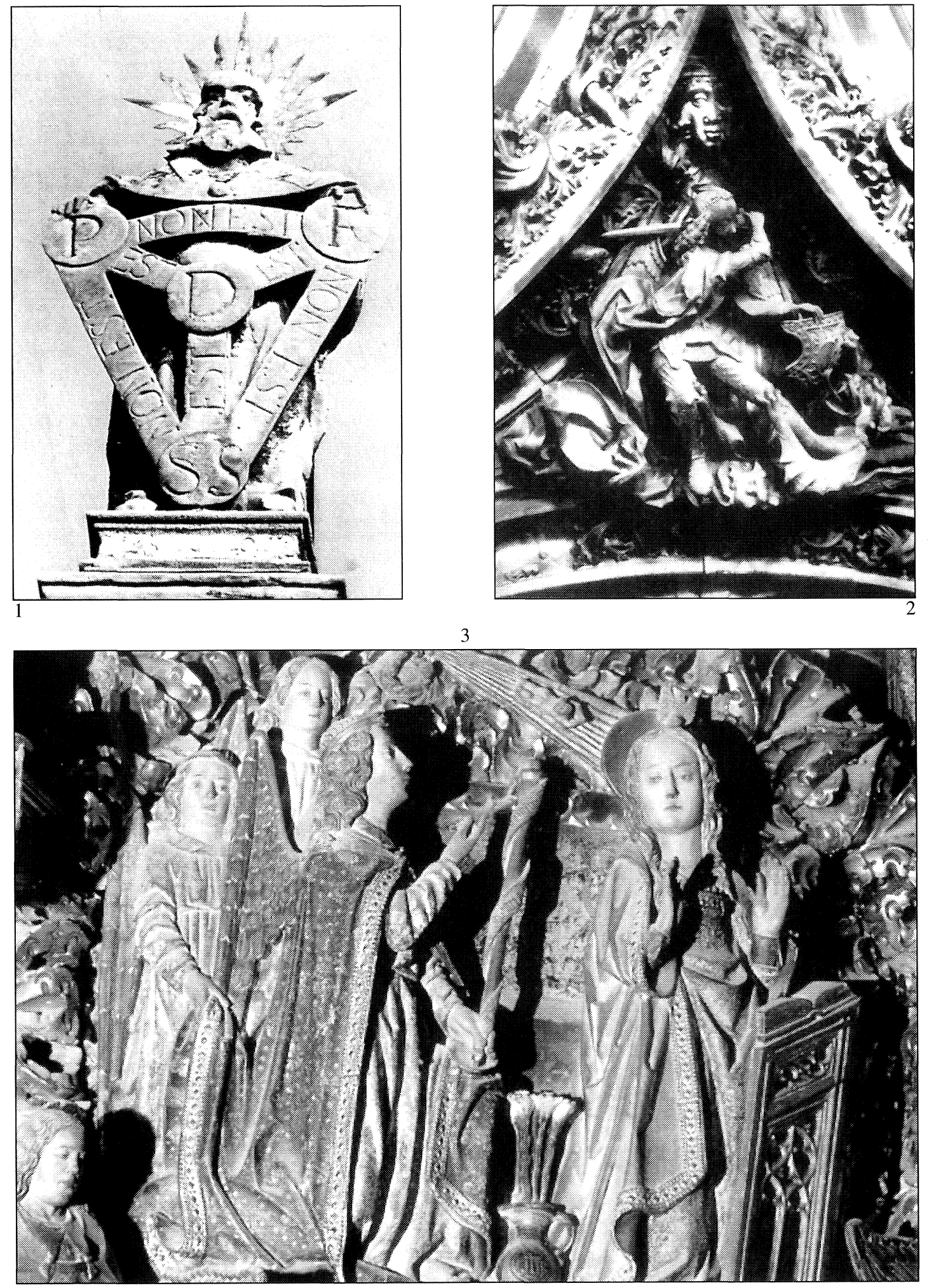

Fig. 1. Remate de la fachada occidental de la iglesia de San Jerónimo de Viena. 1604.

Fig. 2. Gil de Siloé, Sepulcro del Infante Alfonso. Burgos, Cartuja de Miraflores. 1493. Detalle.

Fig. 3. Gil de Siloé. Retablo de la Cartuja de Miraflores. 1499. Detalle. 
San Antonino, III, Tit. VIII, Cap. IV, S. X:

\begin{abstract}
«De carpentariis seu lignariolis. Hi in faciendo ligna incidere secundum augmentum vel decrementum lune sine alia observatione dierum non peccant: quod cum luna ut propinquos planeta multum influat in corpora inferiora: secundum rationem naturalem est quae potius incidant cum luna est in decremento quam in augmento. In faciendo autem diversa opera ex lignis licitum est ex tali exercitio lucrus expetere secundum quantitatem laboris : et industria operis».
\end{abstract}

Como se ha podido comprobar, nuevamente Diego de Cabranes opta por emplear sólo uno de los dos términos utilizados por el arzobispo florentino. Se introduce también aquí otra cuestión que preocupó especialmente a San Antonino: el de la justa remuneración del trabajo, inquietud que recoge en su escrito Diego de Cabranes.

Pasemos, por último, al capítulo XLI, De los pintores:

«La pintura es arte de ministerio honesto sino es mezclado con dolo en lo que es prohibido en los tiempos que no se permite obrar [...] Mas todas estas [obras] son prohibidas en días de fiesta [...] Los que pintan figuras contra la fe haziendo ymagines de ydolos y otras figuras que quiten la devoción del pueblo ansí como es la figura de la Santissima Trinidad que la pintan con tres caras, y a san Juan Baptista con un pellejo de un camello colgando la cabeça y pies, lo qual es monstruo en la naturaleza y falso en la fe por que la Sagrada Escriptura no tiene tal cosa en la verdad [.... Otros muchos errores ay en los cristianos en este oficio que no tan solamente en las cosas profanas son causa de ofender a Dios a su divina magestad con sus invenciones desvariadas y apazibles a los hombres de poca devoción, más aun en las cosas de sus sanctos y templos del culto de Dios, que es más abominable y nefando, pintan invenciones que engendran y conciben pecados pintando mugeres desnudas y otras cosas lasciviosas. Puede haver agravio en este oficio en recebir más de lo justo: estimando la industria del arte más de lo honesto [...] ansí mismo en las colores, obrando con las de baxo valor y cendrarlas con algunas mezclas las quales en breve dan color y andando el tiempo pierden el lustre y vista elegante que tenían».

San Antonino, III, Tit. VIII, Cap. IV, S. XI:

«Pictores non solum secundum quantitatem laboris : sed magis secundum industriam et maiorem peritiam artis de salario sui artificii magis vel minus rationabiliter postulant sibi solvi. Qui in hoc offendunt quando formant imagines provocativas ad libidinem, non ex puchritudine sed ex dispositione earum ut mulieres nudas et huiusmodi. Reprehensibiles etiam sunt cum pingunt ea quae sunt contra fidem, cum faciunt Trinitatis imaginem unam personan cum tribus capitibus quod monstrum est in rerum natura. Vel in Annunciatione Virginis parvulum puerum formatum, scilicet Iesum, mitti in uterum Virginis quasi non esset de substantia Virginis eius corpus assumptum : vel parvulum Iesum cum tabula litterarum, cum non didicerit ab homine. Sed nec etiam laudandi sunt cum apocripha pingunt, ut obstetrices in partu Virginis, Thome apostolo cingulum suum a Virgine Maria in Assumptione sua propter dubitationem eius dimissum, et huismodi. In historiis etiam sanctorum seu in ecclesiis pingere curiosa quae non valent ad devotionem excitandum : sed risum et vanitatem, ut simias et canes insequentes lepores et huismodi, vel vanos ornatus vestimentorum : superfluum videtur et vanum : his haerent miniatores librorum sive cum calamo sive cum penello, quibus etiam competit praemium de labore suo. Offendunt et ipsi si diebus festis hoc agunt, vel quamdo nimium precium exigunt, et maxime cum non bonam temperamenta in coloribus mittunt, propter quod cito delenter de libris».

Este texto presenta una mayor libertad de paráfrasis por parte del autor hispano. Sin embargo, Diego de Cabranes ha tocado todos los temas que San Antonino expone: la prohibición de trabajar en días festivos, la inconveniencia o inmoralidad de algunas imágenes o escenas, y el dolo consistente en utilizar un material menos noble que el pactado, con el fin de lucrarse ilícitamente. En lo que se refiere a ejemplos concretos de imágenes reprobables, Cabranes coincide con el arzobispo florentino en la total impropiedad de la Trinidad trifronte y en el uso del desnudo. Por su parte, San Antonino clama también contra las Anunciaciones en las que aparece el Niño Jesús, ya que podrían llevar a errores doctrinales, algo sobre lo que no se pronuncia Cabranes, quizás porque desconocía tal iconografía

$A E A, \mathrm{LXXV}, 2002,298$, pp. 191 a 216 
que, por cierto, se encuentra, junto con la «monstruosa» Trinidad, en la capilla de Miraflores, Burgos (Figs. 2 y 3$)^{17}$.

Es, precisamente, el texto ahora discutido el que llevó al profesor Checa a realizar la afirmación que citábamos en las primeras líneas de nuestro trabajo: "Falta a la naturaleza, por una parte, y a la fe, por otra, son los ejes sobre los que gira su teoría de la imagen religiosa; y, en esto, Cabranes se muestra de su tiempo y aun anticipador, por lo que respecta al ya señalado contrarreformismo de sus ideas» (p. 60).

A la luz de los paralelos señalados entre la obra del predicador florentino y la del propio Cabranes, debe matizarse la conclusión del profesor Checa. Cabranes depende, para sus ideas estéticas, de un autor que escribe aproximadamente un siglo antes que él y al que citarán profusamente los escritores contrarreformistas:

Entre los primeros que expandieron y concretaron la genérica disposición tridentina acerca de las imágenes sagradas se cuenta Giovanni Andrea Gilio da Fabriano, quien poco después de la última sesión publica su Dialogo nel quale si ragiona degli errori e degli abusi de'pittori circa l'istorie, donde se condena la Trinidad trifronte: Risposi M. Vicenzo: «Più mi pare eretico dipingere la Trinità con tre teste in un sol busto [...] perché, se ben l'essenza è sola, le persona sono distinte, e questo, oltre che lo stimo eretico, lo fo anco mostruoso" ${ }^{18}$.

Johannes Molanus dio a la imprenta en 1570 su De Picturis et Imaginibus Sacris (luego reeditado como De Historia Sanctarum Imaginum et Picturarum). En ella criticaba el uso de la Trinidad de tres caras, aludiendo a la autoridad de San Antonino:

Sanctus Antonius, Florentinus Archiepiscopus, in Summa ubi huiusmodi imaginem vocat monstrum in rerum natura (II, 4) ${ }^{19}$.

El cardenal Gabriele Paleotti, obispo de Bolonia, editó en 1584 su grueso Discorso intorno alle imagine sacre e profane, en cuyo segundo libro de nuevo ataca la iconografía trinitaria que tanto repugnó a San Antonino con similares expresiones: monstruosità di natura y cosa che muove più tosto a nausea che a divozione ${ }^{20}$.

Ya en nuestro país citemos a críticos como Martín de Roa (Antigüedad, veneración i fruto de las Sagradas Imágenes i Reliquias, Sevilla, 1623), Carducho (Diálogos de la pintura, Madrid, 1633) Pacheco (El Arte de la Pintura, Sevilla, 1649) o Palomino, quien sigue a Interián de Ayala («y sobre todos está hoy escribiendo el reverendísimo padre maestro Fray Juan Interián de Ayala») repitiendo el argumento ya conocido («iHaciendo un monstruo la infinita, y suma perfección del Ser de Dios!»), a la par que añade: «y antes que todos la refutó por inicua San Antonino de Florencia» ${ }^{21}$. En 1730 sale de la imprenta el Pictor Christi-

\footnotetext{
17 No es ésta la ocasión para discutir el problema de si el trifaz de Miraflores es o no la Trinidad. Solamente aludiremos al parecido existente entre la idea del sepulcro con San Miguel venciendo al diablo, bajo la tutela del triple rostro (¿cuyo tocado podría ser una interpretación errónea de alguna imagen como la que puede verse en una miniatura paduana de finales de Dugento? Fig. 4) y la escena pintada por Bronzino para la capilla de Eleonora de Toledo en el Palazzo Vecchio de la ciudad del Arno en una fecha (c. 1541) muy próxima a la edición del libro de Cabranes (Fig. 5. Para la miniatura véase A. Rieger, «Ins. e.l cor port, dona, vostra faisso. Image et imaginaire de la femme à travers l'enluminure dans les chansonniers de trobadours», Cahiers de Civilisation Médiévale, XXVIII, 1985, 385-415. Para Bronzino, el monumental trabajo de J. Cox-Rearick, Bronzino's Chapel of Eleonora in the Palazzo Vecchio, Berkeley, 1993).

${ }_{18}$ P. Barocchi (ed.), Trattati d'arte del Cinquecento fra Manierismo e Controriforma, Bari, 1960-61, II, 36.

${ }^{19}$ Ed. de F. Boespflug, O. Christin, B. Tassel, París, 1996.

${ }^{20}$ Barocchi, op. cit., II, p. 422. También el cardenal Roberto Bellarmino criticó en su voluminosa obra Disputationes de controversiis Christianae fidei adversus huius temporis haereticos (1586-93) la utilización de estas imágenes trinitarias en virtud de dos argumentos: el primero, que su aspecto resulta monstruoso, y, segundo y no menos importante, que ciertos protestantes antitrinitarios se burlaban de tales representaciones diciendo que los católicos adoraban a un Cerbero, un Gerión o un Jano trifronte (Nápoles, 1857, II, 479).

${ }^{21}$ A. Palomino, El Museo Pictórico, cit. en F. Calvo Serraller (ed.) Teoría de la pintura del Siglo de Oro, Madrid, 1981, 698 .
}

AEA, LXXV, 2002, 298, pp. 191 a 216 


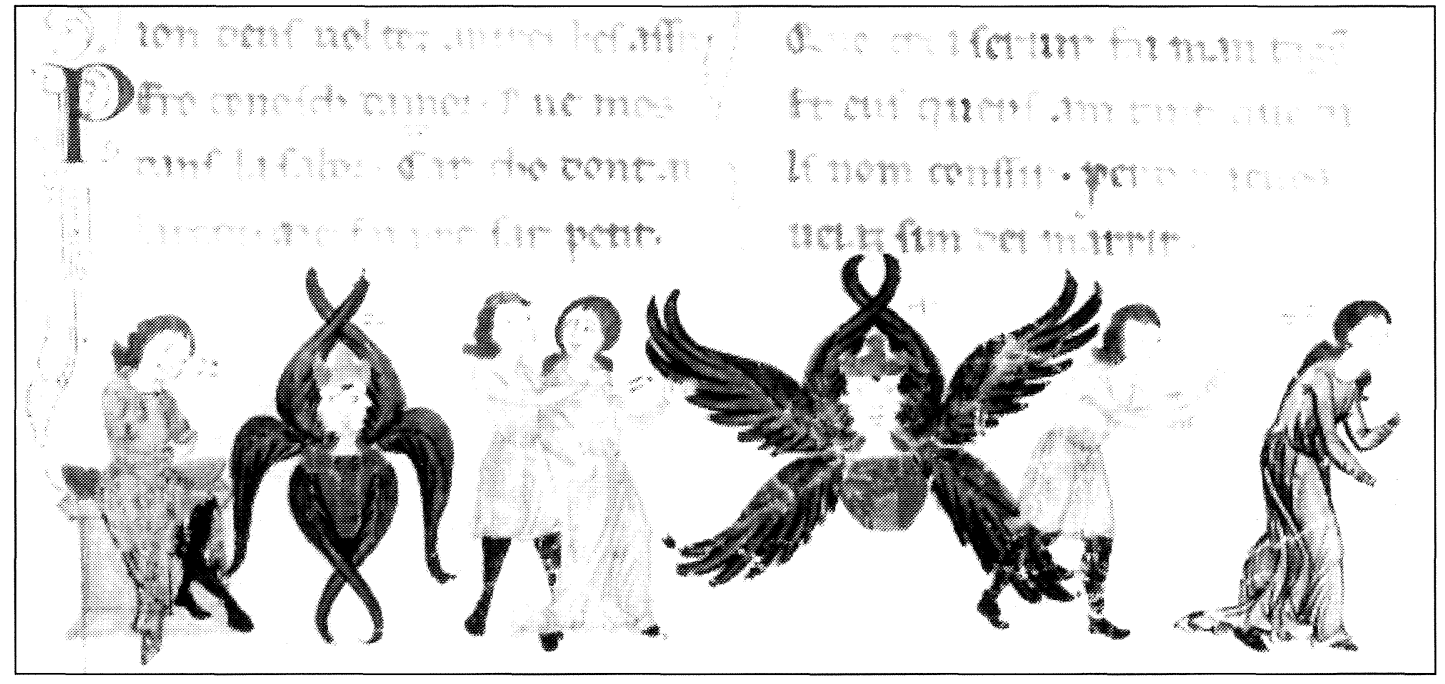

4

5

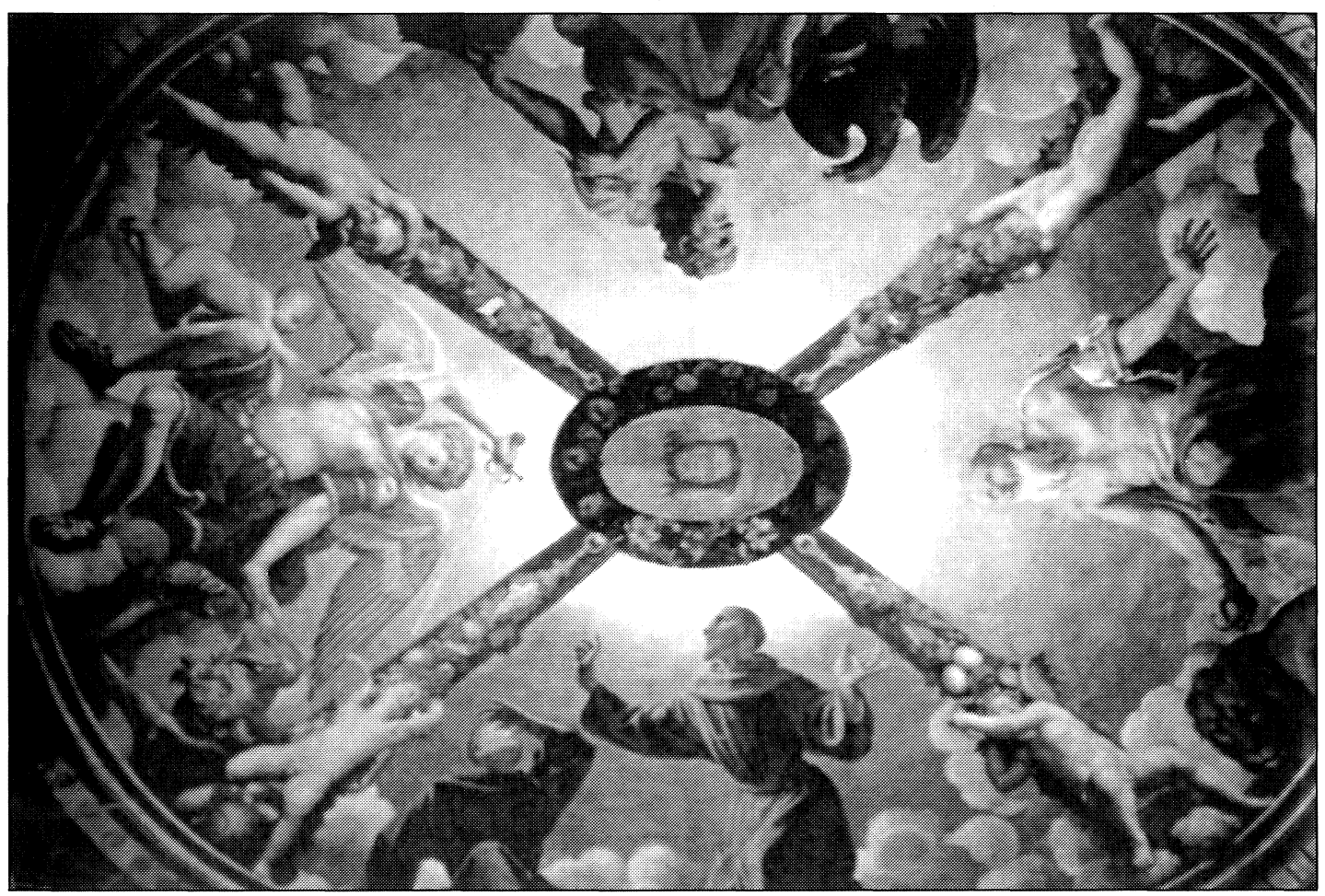

Fig. 4. Chansonnier M. Nueva York, Morgan Library, Ms. M. 819, fol. 56.

Fig. 5. «Il Bronzino». Techo de la Capilla de Eleonora de Toledo. Florencia, Palazzo Vecchio, c. 1541.

AEA, LXXV, 2002, 298, pp. 191 a 216 
anus $^{22}$ del ya aludido fraile mercedario Juan Interián de Ayala, teólogo de la Universidad de Salamanca y miembro de la Real Academia Española, obra que será citada, volviendo a Italia, por el papa Benito XIV en un escrito dirigido al obispo de Augsburgo que puede ser considerado la primera monografía sobre la Trinidad en las artes visuales ${ }^{23}$.

En ninguno de los títulos arriba mencionados se hace alusión a las críticas que Diego de Cabranes realizó de las imágenes impropias en un contexto sagrado, especialmente la de la Trinidad con tres caras o cabezas. Sin embargo, y residiendo buena parte de su autoridad en los escritos de San Antonino, se adelantó el profesor salmantino a toda la ingente literatura postridentina, aunque su obra quedó prácticamente relegada al olvido...

Carlos Sastre VázQuez

\section{A PROPÓSITO DEL BANCO DEL RETABLO DE SAN PELAYO, DEL MAESTRO DE BECERRIL}

Después de desmontarse el retablo del Maestro de Becerril y de su posterior traslado a la catedral de Málaga desde Becerril de Campos ', Angulo citó el banco del retablo en la antigua colección Adanero de Madrid ${ }^{2}$. Al tratar del banco subraya cómo el pintor va renunciando a los fondos de oro berruguetescos ofreciendo más amplitud al paisaje y una sensibilidad estética más afín con Juan de Flandes.

Recientemente, debido a una publicación de quien escribe estas líneas referidas al banco ${ }^{3}$, los actuales propietarios me invitaron a estudiar y ver las tablas, que se hallan en perfecto estado de conservación, colgadas sin marco. Respecto a su estudio poco cabe añadir al entusiasmo demostrado por Angulo a propósito de las calidades de las indumentarias, joyería y paisaje, a cuyo juicio solo hay que añadir más énfasis respecto al espléndido colorido y serena elegancia de Salomón, Ezequiel, acompañado por Hércules y Sansón, en unos relieves del trono - Isaías y David.

Estas breves líneas sólo quieren dar a conocer la pervivencia de las tablas en la colección de los herederos de la antigua colección Adanero, en una época en que a causa del mercado de arte, las tablas circulan más de lo que sería deseable. Aunque la tablas se hallan en perfecto estado, las imágenes que reproducimos son del Archivo Fotográfico Moreno, en donde aparecen con marco y un número de identificación, constando en la antigua colección Adanero (págs. 1-4).

ISABEL MATEO Gómez

\footnotetext{
${ }^{22}$ Pictor christianus eruditus, sive de erroribus qui passim adminttuntur circa pingendas, atque effigendas Sacras Imagines, Madrid, 1730.

${ }^{23}$ F. Boespflug dedicó un ensayo a este documento: Dieu dans l'art. Sollicitudini Nostrae de Benoît XIV (1745) et l'affaire Crescence de Kaufbeuren, París, 1984. Como señaló G. Scavizzi, los problemas planteados a la Iglesia católica tras el cisma protestante fueron responsables de «la nascita dell'archeologia cristiana» («Storia ecclesiastica e arte nel secondo Cinquecento», Storia dell'arte, 59, 1987, 29-46, 38).

I I. Mateo Gómez y J. Mateo Viñes, La Celestina como fuente mitológica para el retablo de San Pelayo, del Maestro de Becerril, Archivo Español de Arte, 1999, p. 289-33.

2 D. Angulo, «Pintura del Renacimiento» en Ars Hispaniae, vol. XII, Madrid, 1954

${ }^{3}$ Catálogo Caylus, «De la Edad Media al Romanticismo», Madrid, 1992-93.
} 